\section{Responsible Innovation for an Ageing Society}

\author{
The Assisted Living Project
}

\author{
by Miltos Ladikas, Institute for Technology \\ Assessment and Systems Analysis (ITAS), \\ Karlsruhe
}

The aging population is a grand challenge to which innovation and technology development must contribute. However, this contribution must be developed in a responsible process with society and not be pushed on society. For this reason we need to build knowledge and experience on how to achieve responsible research and innovation (RRI) in the field of welfare technologies. The Assisted Living project deals with this challenge in Norway and provides comparisons with Germany and UK.

Both EU and Norwegian authorities consider technological development to be an answer to the growing care burden caused by the enormous increase in people with cognitive impairments or dementia. Nearly 36 million people currently suffer from dementia worldwide, a number that is projected to rise to 100 million by 2050 . In Norway, approximately 70,000 persons suffer from a dementia syndrome, a number estimated to increase to 140,000 within the next 35 years (Engedal 2010; WHO/ADI 2012). Technological developments are presumed to assist in the daily living of adults with $\mathrm{MCI} / \mathrm{D}$, as well as prevent and postpone institutionalization (Preschl et al. 2011). The goal is to confront the future lack of labor to carry out the care and to underpin integrity, autonomy, independency, dignity and quality of life.

Assisted living technology is a generic term for a heterogeneous group of technologies, involving for example videophones, robotics, GPS technology and monitoring systems to enhance security and safety and enable people to live an independent everyday life at home and in the community (Norwegian Directorate of Health 2012). Such solutions typically feature

1. sensors with corresponding alarms, e.g. fall sensors, fire sensors and movement sensors including GPS positioning;
2. timer-based monitoring and switch automation solutions, such as light switch controls, oven switches and electronic door locks;

3. calendar-type assistance to help people remember tasks;

4. communication solutions connecting both devices and the person with the outside world, e.g. alarm centers, health personnel, relatives and other care providers.

In addition, other features have been investigated in a number of research studies. However, few studies have documented their efficacy, effectiveness and efficiency (Hofmann 2013).

\section{Assessing benefits and risks}

Various forms of "safety packages" have been implemented in Norway and other European countries (NOU 2011, p. 11). It is not yet clear whether such technology actually reduces the need for manpower and lowers the costs of care, or rather identifies more unmet needs and makes care services dependent on new groups of professionals (i.e. technicians and engineers). In Norway, SINTEF (2012) has initiated promising projects on robot and sensor technology and found out that successful implementation requires socially acceptable, reliable and easyto-use technology. Willingness to install technological solutions at home is high if it enables and empowers the user to live at home (Mihailidis et al. 2008). Providing useful and usable assisted living technologies to persons with mild cognitive impairment and dementia (MCI/D) is, however, not an easy task. A defining feature of people with these conditions is the reduction and loss of the ability to perform everyday activities due to reduced cognitive, emotional and motor performance. However, the symptoms differ from person to person, there may be comorbidities, and, as a result, the cognitive impairment can affect everyday life in various ways (see for instance Hedman et al. 2013).

Many technological solutions have been developed as a result of needs identified by care services, policy makers or the industry. Sävenstedt et al. (2006) found a duality where the formal caregivers perceived assisted living technology 
as a promoter of both inhumane and humane care. The study underlines the importance of ethical discussion concerning the promotion of dignity and quality of life. Zwijsen et al. (2011) discussed how surveillance technology could undermine the relation to the patient and the quality of the care if "caring from distance" reduces face-to-face contact. Certain forms of technology, such as tagging devices, might also cause stigmatization and a loss of privacy and dignity. Although home-based technology is associated with a better quality of life, installed technology is often not in use, and even mundane technology, such as washing machines, may seldom be used (Matlabi 2011). On the other hand, many persons with MCI/D are influenced by, and are also users of, everyday technologies such as remote controls, mobile phones and digital household appliances.

Only a few studies have researched the need for technological solutions from the perspective of persons living with MCI/D (Topo 2009; Mulvenna/Nugent 2010). In translating these often broadly defined needs into actual and usable compensatory technological solutions, this group is too often left out, even though studies have demonstrated that persons with MCI are indeed capable of giving their opinions on the user-friendliness and usefulness of assistive technology (Meiland et al. 2013).

\section{The Assisted Living project}

The transdisciplinary Assisted Living project ${ }^{1}$ conducts research within ICT, health science, social science and ethics. The overall aim of the project is to advance responsible research and innovation (RRI) in the field of welfare technology. By adapting an RRI framework, the project aims to:

a) map how stakeholders and experts perceive the state-of-the-art of responsible welfare technologies, focusing on assisted living technologies in Norway and all over the world;

b) develop assisted living technology solutions for users with MCI/D through an RRI approach; c) judge by an integrated HTA approach whether technologies introduced through an RRI process score better than currently implemented technologies; and

d) create a wider dialogue on responsible welfare technologies for the future, reflecting on alternatives and options.

The project explicitly develops RRI as an integrated learning process and governance approach while at the same time performing research on RRI, targeting the needs of the aging population as a global challenge in welfare provision and developing competence and capacity on responsible innovation within welfare technology development, but also within the care professions, in the shorter and longer term. The project consolidates several research and development groups, led by Oslo and Akershus University (Ellen-Marie Forsberg), into a strong cross-faculty and cross-institutional research group on responsible assisted living technologies, including students and researchers at all levels as well as international partners (Owen (Exeter), ter Meulen (Bristol) and Ladikas (Karlsruhe)). Moreover, the project will cooperate extensively with regional actors, such as municipal care providers, and national actors, such as interest organizations and the Norwegian Board of Technology (NBT), and the industry (Sensio AS).

Two main aspects of RRI will be further developed in this project: RRI as a process of participatory technology development and RRI dimensions integrated in an approach for technology appraisal.

This approach will assess whether current practices for introducing assisted living technologies for people with $\mathrm{MCI} / \mathrm{D}$ living at home are considered responsible and whether innovations developed in an RRI process indeed meet the RRI goals expressed in the six EC key dimensions (translated into an adapted HTA approach). In this project the RRI approach will be applied to the assisted living technologies introduced in the project and compared to current technologies. This requires a study of the current situation in order to compare it with the technology development carried out in the project. 


\section{Note}

1) The project is funded by the Research Council of Norway for the period 2016-2019, see https://hioaresponsibleinnovation.wordpress.com/projects/ the-assisted-living-project.

\section{References}

Engedal, K., 2010: The Norwegian Dementia Plan 2015 - "Making Most of the Good Days". In: International Journal of Geriatric Psychiatry 25/9 (2010), pp. 928-930; doi:10.1002/gps.2601. Retrieved from PM: 20803724

Hedman, A.; Nygård, L.; Almkvist, O. et al., 2013: Patterns of Functioning in Older Adults with Mild Cognitive Impairment: A Two-year Study Focusing on Everyday Technology Use. In: Aging \& Mental Health 17/6 (2013), pp. 679-688

Hofmann, B., 2013: Ethical Challenges with Welfare Technology: A Review of the Literature. In: Science and Engineering Ethics, 19/2 (2013), pp. 389-406

Matlabi, H.; Parker, S.G.; McKee, K., 2011: The Contribution of Home-based Technology to Older People's Quality of Life in Extra Care Housing. In: BMC Geriatrics 11/68 (2011); http://bmcgeriatr.biomedcentral.com/articles/10.1186/1471-2318-11-68 (download 8.4.16)

Meiland, F.J.M.; Hattink, B.J.J.; Overmars-Marx, T. et al., 2013: Participation of End Users in the Design of Assistive Technology for People with Mild to Severe Cognitive Problems. The European Rosetta Project. In: International Psychogeriatrics 26/5 (2013), pp. 769-779

Mihailidis, A.; Cockburn, A.; Longley, C. et al., 2008: The Acceptability of Home Monitoring Technology Among Community-dwelling Older Adults and Baby Boomers. In: Assistive Technology 20/1 (2008), pp. $1-12$

Mulvenna, M.D.; Nugent, C.D. (eds.), 2010: Supporting People with Dementia Using Pervasive Health Technologies, Advanced Information and Knowledge Processing. London

Norwegian Directorate of Health, 2012: Velferdsteknologi. Fagrapport om implementering av velferdsteknolgi i de kommunale helse- og omsorgstjenestene (Welfare Technology. Report on the Implementation of Welfare Technology in the Municipal Healthcare) 2013-2030 (06/2012). Oslo

NOU - Norges offentlige utredninger, 2011: Innovasjon i omsorg (Innovation in Caring) 2011, p. 11
Preschl, B.; Wagner, B.; Forstmeier, S. et al., 2011: E-health Interventions for Depression, Anxiety Disorder, Dementia, and Other Disorders in Older Adults: A review. In: Journal of Cybertherapy and Rehabilitation 4/3 (2011), pp. 371-385

Sävenstedt, S.; Sandman, P.O.; Zingmark, K., 2006: The Duality in Using Information and Communication Technology in Elder Care. In: Journal of Advanced Nursing 56/1 (2006), pp. 17-25

SINTEF - Stiftelsen for industriell og teknisk forskning, 2012: Trygghetspakken - behovkartlegging og erfaringer [Security Package - identifying needs and experiences]; https://www.sintef.no/globalassets/ project/velferdsteknologi/trygghetspakken/trygghetspakke-behovskartlegging_innomed-forprosjekt-juni-2012.pdf (download 15.3.16)

Topo, P., 2009: Technology Studies to Meet the Needs of People with Dementia and Their Caregivers. A LiteratureReview. In: Journal of Applied Gerontology, 28/1 (2009), pp. 5-37

WHO - World Health Organization; ADI - Alzheimer's Disease International, 2012: Dementia: A Public Health Priority; http:/www.who.int/mental_health/publications/dementia_report_2012/en/ (download 9.3.16)

Zwijsen, S.A.; Depla, M.F.I.A.; Niemeijer, A.R. et al., 2012: Surveillance Technology: An Alternative to Physical Restraints? A Qualitative Study Among Professionals Working in Nursing Homes for People with Dementia. In: International Journal of Nursing Studies, 49/2 (2012), pp. 212-219

\section{Contact}

Dr. Miltos Ladikas

Institute for Technology Assessment and Systems

Analysis (ITAS)

Karlsruhe Institute of Technology (KIT)

Karlstraße 11, 76133 Karlsruhe

Email: miltos.ladikas@kit.edu 